\title{
Predictors of Acute Radiation Esophagitis in Non-small Cell Lung Cancer Patients Treated With Accelerated Hyperfractionated Chemoradiotherapy
}

\author{
KENTARO WADA $^{1 *}$, NORIKO KISHI ${ }^{1}$, NAOYUKI KANAYAMA ${ }^{1}$, TAKERO HIRATA ${ }^{1}$, \\ YOSHIHIRO UEDA ${ }^{1}$, YOSHIFUMI KAWAGUCHI ${ }^{1}$, MASAHIRO MORIMOTO ${ }^{1}$, \\ KOJI KONISHI ${ }^{1}$, FUMIO IMAMURA ${ }^{2}$, KAZUHIKO OGAWA ${ }^{3}$ and TERUKI TESHIMA ${ }^{1}$ \\ ${ }^{1}$ Department of Radiation Oncology, Osaka International Cancer Institute Hospital, Osaka, Japan; \\ ${ }^{2}$ Department of Thoracic Oncology, Osaka International Cancer Institute Hospital, Osaka, Japan; \\ ${ }^{3}$ Department of Radiation Oncology, Osaka University Graduate School of Medicine, Osaka, Japan
}

\begin{abstract}
Background/Aim: To identify the clinical and dosimetric predictors of severe acute radiation esophagitis (RE) in patients with non-small cell lung cancer (NSCLC) treated with accelerated hyperfractionated concurrent chemoradiotherapy (AH-CCRT) with concomitant boost technique. Patients and Methods: A total of 159 patients who underwent AH-CCRT (64 Gy in 40 fractions twice daily) were retrospectively identified. Severe RE was designated as grade 3 or higher according to the Common Terminology Criteria for Adverse Events, version 4.0. Results: The incidence rate of grade 3 RE was $15.1 \%$ (24/159). The multivariate analysis that incorporated the Eastern Cooperative Oncology Group performance status (ECOG PS, $\geq 1$ vs. 0 ) and the relative esophagus volume irradiated with at least $60 \mathrm{~Gy}\left(V_{60}\right)$ was optimal. Patients with a $V_{60}$ of $\geq 15 \%$ had a $37.8 \%$ risk of grade 3 RE compared to a $6.1 \%$ risk among those with a $V_{60}$ of $<15 \%$. Conclusion: ECOG PS $(\geq 1$ vs. 0$)$ and the $V_{60}$ were found to be significant risk factors for severe RE in NSCLC patients who underwent $A H-C C R T$.
\end{abstract}

Non-small cell lung cancer (NSCLC) is a major cause of death worldwide. The standard of care for patients with locally

This study was presented in part as poster at the 59th Annual Meeting of the American Society for Radiation Oncology, San Diego, CA. September 2017.

Correspondence to: Kentaro Wada, Department of Radiation Oncology, Osaka International Cancer Institute Hospital, 3-1-69 Otemae, Chuoku, Osaka 541-8567, Japan.e-mail: k_wada@radonc.med.osaka-u.ac.jp

Key Words: Radiation esophagitis, non-small cell lung cancer, chemoradiation, accelerated hyperfractionation, concomitant boost technique. advanced NSCLC is definitive concurrent chemoradiotherapy (CCRT); however, the local control rate following this therapy remains poor (1). Although the efficacy of dose escalation is unclear, treatment using accelerated hyperfractionated radiotherapy (AHRT) was previously shown to improve local control and overall survival (OS) (2-4). A phase 2 study and a propensity matched analysis showed that accelerated hyperfractionated concurrent chemoradiotherapy (AH-CCRT) (64 Gy in 40 fractions twice daily) resulted in an excellent response rate and OS $(5,6)$.

Approximately $10-20 \%$ of patients undergoing CCRT will experience severe radiation esophagitis (RE) $(1,7,8)$. The symptoms include retrosternal pain, dysphagia and odynophagia. Assessing the risk of severe RE is a critical step in choosing treatment intensification strategy using AH-CCRT, as severe RE often leads to the interruption of treatment (9), which spoils the advantage of shortened radiation treatment time (RTT) of AH-CCRT regimens. Clinical and dosimetric risk factors for RE reported from standard once-daily regimens cannot necessarily be applied to twice-daily regimens. In this study, we sought to identify clinical and dosimetric factors for severe RE in a cohort of patients with NSCLC treated with a twice-daily AH-CCRT regimen.

\section{Materials and Methods}

Patient population and pretreatment evaluation. After institutional review board approval (No.1606309044) was obtained, a retrospective review was performed. A total of 159 patients with NSCLC treated with AH-CCRT were identified between 2004 and 2017. Clinical factors included sex, age, Eastern Cooperative Oncology Group performance status (ECOG PS), body mass index (BMI), treatment period, $\mathrm{N}$ classification and chemotherapy status (including chemotherapy cycle upon concurrent RT commencement, consolidation chemotherapy use and the concurrent chemotherapy regimen). The clinical stage was not included because the edition 
(the 6th or 7th) of the Union for International Cancer Control (UICC) that was used for staging could not be determined in some patients. The $\mathrm{N}$ classification was included because it did not change between the 6 th and 7 th editions of the UICC. BMI was defined as weight in kilograms divided by the square of height in meters. Patient characteristics are presented in Table I.

RT technique. All patients were treated with 3-dimensional conformal RT. The planning technique was based on the International Commission on Radiation Units and Measurements, report 62 (10). The gross tumor volume (GTV) was defined as the primary tumor and metastatic nodes. The clinical target volume (CTV) consisted of the high-risk CTV (CTV1: GTV plus a 5-mm margin) and elective CTV (CTV2: CTV1 plus elective nodal areas of the mediastinum). The CTV1 and CTV2 were expanded by $5 \mathrm{~mm}$ to define the planning target volumes (PTV1 and PTV2). Organs at risk were contoured on the expiratory scan. Typical field arrangements consisted of 4 beams, usually anterior-posterior opposed fields for PTV2 and oblique opposed fields for PTV1. The concomitant boost was defined as the boost irradiation for PTV1, which in standard once-daily RT is typically started after the end of irradiation for PTV2, but was instead started at the beginning of the treatment. The prescribed dose was 64 Gy over 4 weeks with the concomitant boost technique (phase 1: 40 Gy/20 fractions for PTV2; phase 2: 24 Gy/20 fractions as a second daily fraction after a 6 hours gap for PTV1) (5). Radiation was delivered between Monday and Friday. Holiday- and machine maintenance-associated days off were considered treatment breaks.

Esophageal contouring and dosimetric parameters. For consistency, the esophagus was re-delineated in all patients by the same radiation oncologist (K.W.). The esophageal contour extended from the inferior margin of the cricoid cartilage superiorly to the gastroesophageal junction inferiorly. The esophageal contour was not expanded to account for setup variability. Dosimetric analyses included reporting the maximal esophageal dose (Dmax), mean esophageal dose $\left(D_{\text {mean }}\right)$, esophageal volume (in $\left.\mathrm{cm}^{3}\right)$, and the relative volume of the esophagus receiving at least $\times \mathrm{Gy}\left(\mathrm{V}_{10-60}\right)$. Based on the hypothesis that length is important when predicting severe RE, the lengths of the esophageal sections receiving at least the mean dose of $\times$ Gy $\left(\mathrm{L}_{10-60}\right)$ were also calculated.

Chemotherapy. Cisplatin $\left(80 \mathrm{mg} / \mathrm{m}^{2}\right)$ on day 1 combined with vinorelbine $\left(25 \mathrm{mg} / \mathrm{m}^{2}\right)$ on days 1 and 8 in 3- to 4-weeks intervals were delivered as concurrent chemotherapy in 114 patients, and carboplatin plus paclitaxel were administered to 36 patients with comorbidities. Six patients received both cisplatin and carboplatin with varying cycles, 1 received cisplatin plus docetaxel, and 2 received cisplatin plus S-1. RT commenced with the first chemotherapy cycle in $52.8 \%$ of the patients and with the second or third cycle in $47.2 \%$. Consolidation chemotherapy was administered to $77.4 \%$ of the patients.

Esophagitis scoring and follow-up. RE was retrospectively graded according to National Cancer Institute's Common Terminology Criteria for Adverse Events version 4.0 from the start of RT until 3 months afterward. Severe acute RE was designated grade 3 or above. Evaluation for acute toxicity during the treatment course was performed once a week or more frequently when interventions were indicated. The first follow-up clinical evaluation was performed 12 weeks after completion of RT and every 1-3 months thereafter.
Table I. Patient characteristics.

\begin{tabular}{|c|c|c|}
\hline Characteristics & $\begin{array}{l}\text { Number } \\
(\mathrm{N}=159)\end{array}$ & $\begin{array}{l}\text { Percentage } \\
\quad(\%)\end{array}$ \\
\hline \multicolumn{3}{|l|}{ Age (years) } \\
\hline Median (range) & $63(34-79)$ & - \\
\hline$<70 / \geq 70$ & $127 / 32$ & $79.9 / 20.1$ \\
\hline \multicolumn{3}{|l|}{ Gender } \\
\hline Male/Female & $130 / 29$ & $81.8 / 18.2$ \\
\hline \multicolumn{3}{|l|}{ ECOG PS } \\
\hline $0 / 1-2$ & $102 / 57$ & $64.2 / 35.8$ \\
\hline \multicolumn{3}{|l|}{ BMI $\left(\mathrm{kg} / \mathrm{m}^{2}\right)$} \\
\hline Median (range) & $21.9(15.9-30.2)$ & \\
\hline$<22 / \geq 22$ & $81 / 78$ & $50.9 / 49.1$ \\
\hline \multicolumn{3}{|l|}{ Treatment period } \\
\hline 2004-2009/2010-2017 & $67 / 92$ & $42.1 / 57.9$ \\
\hline \multicolumn{3}{|l|}{$\mathrm{N}$ classification } \\
\hline $0 / 1 / 2 / 3$ & $11 / 19 / 88 / 41$ & $6.9 / 11.9 / 55.3 / 25.8$ \\
\hline \multicolumn{3}{|l|}{ Histology } \\
\hline SCC/AC/NSCLC-NOS & $60 / 84 / 15$ & $37.7 / 52.8 / 9.4$ \\
\hline \multicolumn{3}{|l|}{ Chemotherapy } \\
\hline Cisplatin + vinorelbine & 114 & 71.7 \\
\hline Carboplatin + paclitaxel & 36 & 22.6 \\
\hline Others & 9 & 5.6 \\
\hline \multicolumn{3}{|l|}{$\begin{array}{l}\text { RT started with } 1 \text { st } \\
\text { chemotherapy cycle }\end{array}$} \\
\hline Yes/No & $84 / 75$ & $52.8 / 47.2$ \\
\hline \multicolumn{3}{|l|}{ Consolidation chemotherapy } \\
\hline Yes/No & $118 / 41$ & $74.2 / 25.8$ \\
\hline \multicolumn{3}{|l|}{ RT delay $\geq 5$ days } \\
\hline Yes/No & $39 / 120$ & $24.5 / 75.5$ \\
\hline \multicolumn{3}{|l|}{ Volume of esophagus $\left(\mathrm{cm}^{3}\right)$} \\
\hline Median (range) & $35.5(20.5-68.5)$ & - \\
\hline \multicolumn{3}{|l|}{ Length of esophagus $(\mathrm{cm})$} \\
\hline Median (range) & $24.3(21.0-29.0)$ & - \\
\hline \multicolumn{3}{|c|}{ Maximum esophagus dose (Gy) } \\
\hline Median (range) & $63.6(37.8-68.7)$ & - \\
\hline \multicolumn{3}{|l|}{ Mean esophagus dose (Gy) } \\
\hline Median (range) & $23.8(6.0-44.8)$ & - \\
\hline
\end{tabular}

ECOG PS: Eastern Cooperative Oncology Group performance status; BMI: body mass index; SCC: squamous cell carcinoma; AC: adenocarcinoma; NSCLC-NOS: non-small cell lung cancer not otherwise specified; RT: radiotherapy.

Statistical analysis. Clinical and dosimetric factors were analyzed to determine the risk factors associated with the development of grade $\geq 3$ RE. First, univariate analyses were performed to identify any significant risk factors from among the following: sex, age, ECOG PS, BMI, treatment period, $\mathrm{N}$ classification, chemotherapy status, and dosimetric parameters (including Dmax, Dmean, the relative volumetric variables $\left[\mathrm{V}_{10}, \mathrm{~V}_{20}, \mathrm{~V}_{30}, \mathrm{~V}_{40}, \mathrm{~V}_{45}, \mathrm{~V}_{50}, \mathrm{~V}_{55}\right.$, and $\left.\mathrm{V}_{60}\right]$ and the absolute length variables $\left[\mathrm{L}_{10}, \mathrm{~L}_{20}, \mathrm{~L}_{30}, \mathrm{~L}_{40}, \mathrm{~L}_{50}\right.$, and $\left.\mathrm{L}_{60}\right]$ ). The chi-square test was used to confirm independence among clinical factors. Pearson's analysis was performed to calculate the correlation between dosimetric factors. Secondly, multivariate analyses of significant $(p<0.05)$ and marginally significant $(p<0.1)$ factors were performed using a multiple logistic regression model. The Akaike information criterion (AIC), which balances the 
Table II. Univariate analysis of clinical and dosimetric factors associated with radiation esophagitis.

\begin{tabular}{|c|c|c|c|c|}
\hline & OR & 95\%CI lower & 95\%CI upper & $p$-Value \\
\hline Age $(\geq 70 v s .<70)$ & 0.52 & 0.15 & 1.87 & 0.32 \\
\hline Gender (male vs. female) & 1.14 & 0.36 & 3.62 & 0.83 \\
\hline ECOG PS ( $\geq 1 v s .0)$ & 4.59 & 1.82 & 11.56 & 0.001 \\
\hline BMI $\left(<22 v s . \geq 22 \mathrm{~kg} / \mathrm{m}^{2}\right)$ & 0.79 & 0.33 & 1.88 & 0.58 \\
\hline Treatment period (2004-2009 vs. 2010-2017) & 1.19 & 0.5 & 2.86 & 0.69 \\
\hline $\mathrm{N}$ classification $(0-1$ vs. $2-3)$ & 1.05 & 0.36 & 3.07 & 0.93 \\
\hline Chemotherapy regimen (Carboplatin + paclitaxel vs. others) & 1.51 & 0.57 & 3.98 & 0.41 \\
\hline Radiotherapy started with 1 st chemotherapy cycle (yes $v s$. no) & 1.39 & 0.58 & 3.33 & 0.46 \\
\hline Consolidation chemotherapy (yes vs. no) & 0.82 & 0.31 & 2.14 & 0.68 \\
\hline Mean dose & $1.21 *$ & 1.10 & 1.32 & $<0.001$ \\
\hline Maximum dose & $1.35^{*}$ & 1.09 & 1.66 & 0.006 \\
\hline $\mathrm{V}_{10}$ & $1.83^{*}$ & 1.15 & 2.93 & 0.008 \\
\hline $\mathrm{V}_{20}$ & $2.09 *$ & 1.28 & 3.42 & 0.001 \\
\hline $\mathrm{V}_{30}$ & $2.20^{*}$ & 1.35 & 3.60 & 0.002 \\
\hline $\mathrm{V}_{40}$ & $2.03^{*}$ & 1.34 & 3.07 & $<0.001$ \\
\hline$V_{45}$ & $2.03^{*}$ & 1.44 & 2.85 & $<0.001$ \\
\hline $\mathrm{V}_{50}$ & $2.09^{*}$ & 1.49 & 2.93 & $<0.001$ \\
\hline $\mathrm{V}_{55}$ & $2.16^{*}$ & 1.54 & 3.04 & $<0.001$ \\
\hline $\mathrm{V}_{60}^{53}$ & $2.35^{*}$ & 1.63 & 3.39 & $<0.001$ \\
\hline $\mathrm{L}_{10}$ & $1.21^{*}$ & 1.0 & 1.45 & 0.047 \\
\hline $\mathrm{L}_{20}$ & $1.31^{*}$ & 1.09 & 1.58 & 0.005 \\
\hline $\mathrm{L}_{30}$ & $1.31^{*}$ & 1.09 & 1.57 & 0.005 \\
\hline $\mathrm{L}_{40}$ & $1.26^{*}$ & 1.08 & 1.47 & 0.004 \\
\hline $\mathrm{L}_{50}$ & $1.27^{*}$ & 1.12 & 1.44 & $<0.001$ \\
\hline $\mathrm{L}_{60}$ & $1.31 *$ & 1.15 & 1.50 & $<0.001$ \\
\hline
\end{tabular}

OR: Odds ratio; CI: confidence interval; ECOG PS: Eastern Cooperative Oncology Group performance status; BMI: body mass index; $\mathrm{V}_{10} \mathrm{~V}_{60}$ : percentages of volumes receiving at least the respective dose; $\mathrm{L}_{10}-\mathrm{L}_{60}$ : esophageal lengths receiving at least the mean of the respective dose. $* \mathrm{OR}$ for change of $1 \mathrm{~Gy}$ (mean dose and maximum dose), $10 \%$ relative volume $\left(\mathrm{V}_{10-60}\right), 1 \mathrm{~cm}\left(\mathrm{~L}_{10-60}\right)$.

goodness of fit with the complexity of the model, was used for backward model selection of the dosimetric parameters. The preferred model was that exhibiting the lowest AIC value. Additionally, receiver operating characteristic (ROC) curves were used to identify cutoff values for dosimetric predictors. All statistical tests were 2-sided. JMP Pro version 10 (SAS Institute Inc., Cary, NC, USA) was used for the statistical analysis.

\section{Results}

Of the 159 patients included in this study, $81.8 \%$ were men and $18.2 \%$ were women; their median age was 63 years (range $=34-79$ years). Of these patients, 151 were receiving their first treatment while 8 were receiving salvage RT for regional lymph node recurrence after surgery. The incidence rate of grade $3 \mathrm{RE}$ was $15.1 \%$ (24/159); no grade 4 or $5 \mathrm{RE}$ was observed. The median time to RE onset upon commencing RT and the median duration of RE were 26 (range=16-52 days) and 11 days (range=3-23 days), respectively. Furthermore, 26 of 135 patients with RE grade $<3(19.3 \%)$ experienced treatment delays of over 5 days during RT, whereas 13 of 24 patients with RE grade 3
(54.2\%) experienced such delays. Patients who were $\geq 70$ years tended to commence RT with the first chemotherapy cycle $(p=0.04)$; moreover, a weekly carboplatin + paclitaxel regimen was more prevalent $(p=0.035)$. No other associations were detected among the clinical factors.

On univariate analysis, only ECOG PS ( $\geq 1 v s .0)$ was a significant factor for grade $3 \mathrm{RE}$. Sex, age, BMI, treatment period, $\mathrm{N}$ classification and chemotherapy status were not significant factors. The dosimetric parameters, $\mathrm{D}_{\text {max }}, \mathrm{D}_{\text {mean }}$, relative volumetric variables $\left(\mathrm{V}_{10-60}\right)$ and absolute length variables $\left(\mathrm{L}_{10-60}\right)$ were all significantly correlated with grade $3 \mathrm{RE}$. The average Dmean and Dmax of grade $\leq 2 \mathrm{RE}$ and grade $\geq 3 \mathrm{RE}$ were $22.7 \mathrm{~Gy} v s .29 .1 \mathrm{~Gy}(p<0.0001)$ and 61.2 Gy $v s .64 .8$ Gy $(p=0.007)$, respectively. Associated odds ratios (ORs) are shown in Table II. The average esophageal volume variables are shown in Figure 1 and the average esophageal length variables are shown in Figure 2.

Multivariate analysis was performed on the dosimetric variables and ECOG PS ( $1 \geq v s .0)$. Spearman's correlation coefficient test did not show any associations between the dosimetric variables and ECOG PS. Because of the 


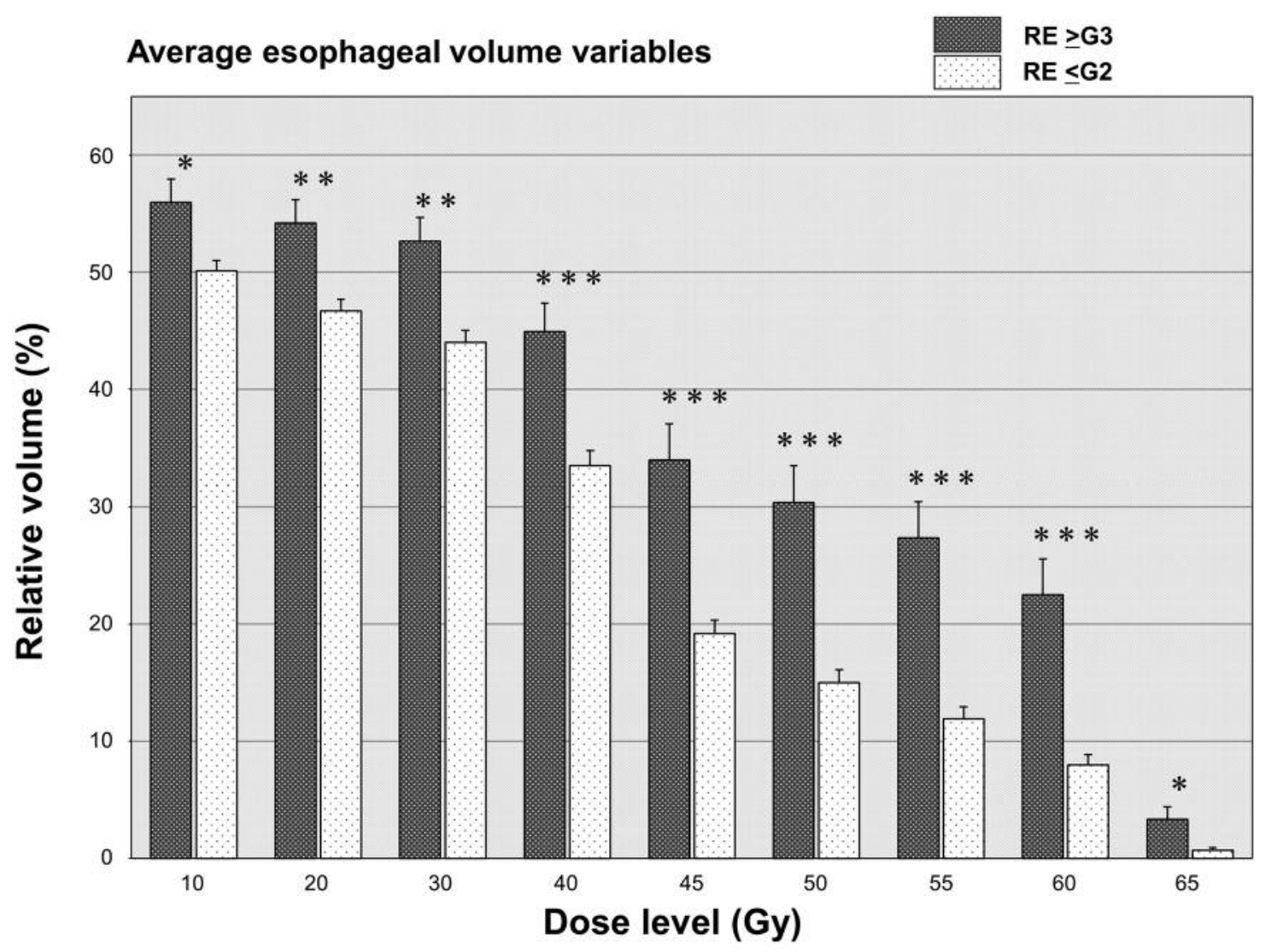

Figure 1. Average esophageal volume variables for patients with radiation esophagitis of grades $\geq 3$ ( $R E \geq G 3)$ and patients with $R E \leq G 2$. The error bars denote the $95 \%$ standard error. Both groups were compared at each dose level using a two-sided Student's t-test $\left({ }^{*} p<0.05, * * p<0.01\right.$, $* * * p<0.001)$.

multicollinearity between dosimetric variables, which was confirmed by Pearson's analysis, the multivariate analysis was applied separately for each dosimetric parameter. The AIC values of the logistic models with ECOG PS and each dosimetric parameter are shown in Table III. All models demonstrated a significant correlation between grade $3 \mathrm{RE}$ and the predictor variables. The length metrics $\left(\mathrm{L}_{10}-\mathrm{L}_{60}\right)$ had higher AIC values than the corresponding value for $\mathrm{D}_{\text {mean }}$ and volume metrics. The model containing ECOG PS and $\mathrm{V}_{60}$ was optimal with the lowest AIC value of 105.9. An ECOG PS $\geq 1$ (OR: $5.1,95 \%$ confidence interval $(\mathrm{CI})=1.78-14.6)$ and a larger $\mathrm{V}_{60}(\mathrm{OR}$ for change of $10 \%$ relative volume: $2.45,95 \% \mathrm{CI}=1.64-3.64)$ significantly increased the risk of grade $3 \mathrm{RE}$. On the ROC curve analysis, the area under the ROC curve was 0.79 $(95 \% \mathrm{CI}=0.69-0.90)$. This curve and the corresponding AUC showed that the $\mathrm{V}_{60}$ had a moderate predictive ability for grade $3 \mathrm{RE}$; a $\mathrm{V}_{60}$ of $<15 \%$ produced a $6.1 \%$ occurrence rate for grade $3 \mathrm{RE}$, which increased to $37.8 \%$ if the $\mathrm{V}_{60}$ was $\geq 15 \%$.
Table III. Akaike information criterion scores of the models.

\begin{tabular}{ll}
\hline Dosimetric parameters & AIC \\
\hline Mean dose & 108.9 \\
Maximum dose & 116.2 \\
$\mathrm{~V}_{10}$ & 122.0 \\
$\mathrm{~V}_{20}$ & 119.7 \\
$\mathrm{~V}_{30}$ & 118.2 \\
$\mathrm{~V}_{40}$ & 115.7 \\
$\mathrm{~V}_{45}$ & 111.3 \\
$\mathrm{~V}_{50}$ & 108.9 \\
$\mathrm{~V}_{55}$ & 107.6 \\
$\mathrm{~V}_{60}$ & 105.9 \\
$\mathrm{~L}_{10}$ & 125.8 \\
$\mathrm{~L}_{20}$ & 121.7 \\
$\mathrm{~L}_{30}$ & 121.2 \\
$\mathrm{~L}_{40}$ & 119.9 \\
$\mathrm{~L}_{50}$ & 114.4 \\
$\mathrm{~L}_{60}$ & 114.7 \\
\hline
\end{tabular}

AIC: Akaike information criterion; $\mathrm{V}_{10}-\mathrm{V}_{60}$ : percentages of volumes receiving at least the respective dose; $\mathrm{L}_{10}-\mathrm{L}_{60}$ : esophageal lengths receiving at least the mean respective dose. 


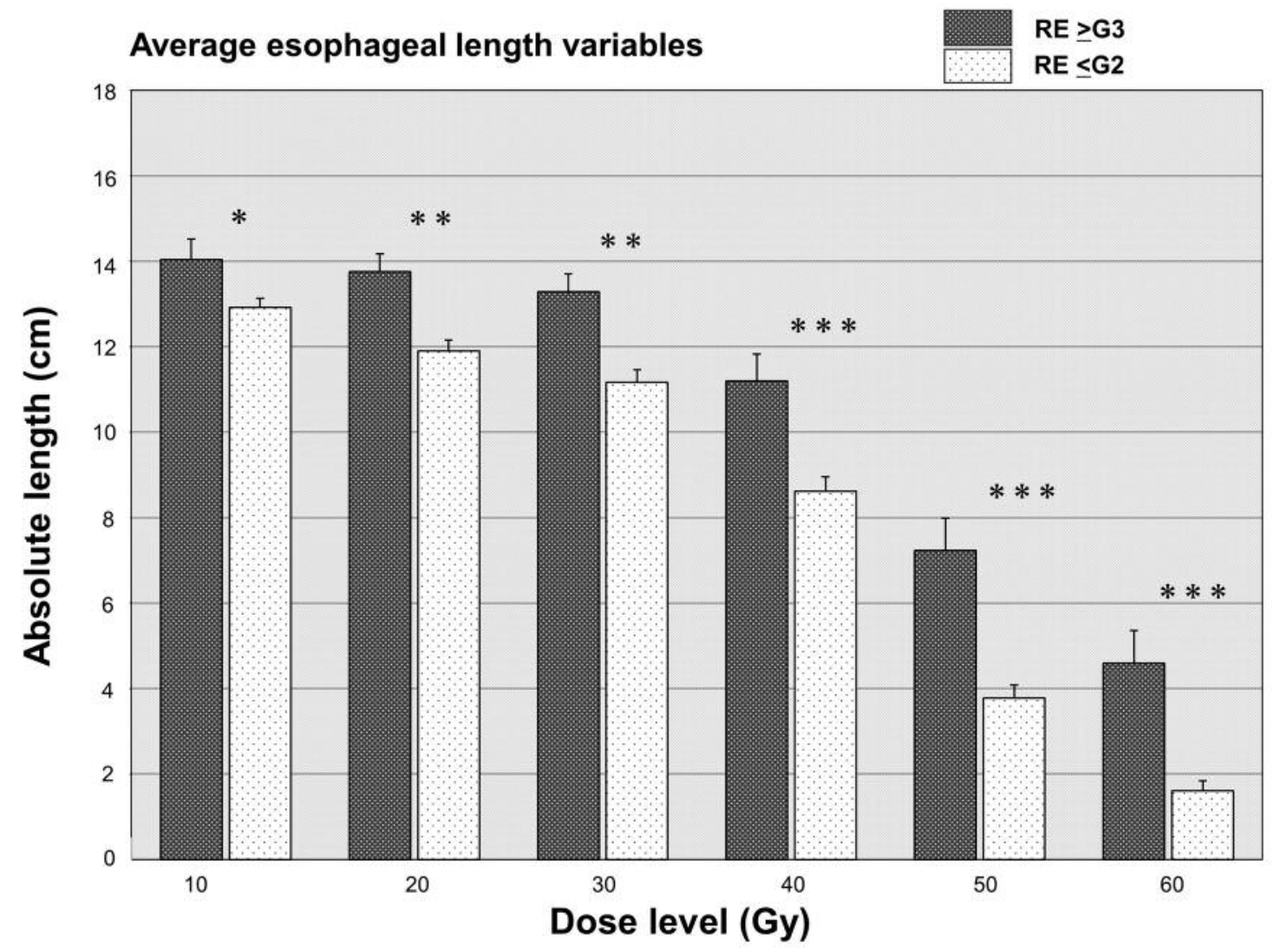

Figure 2. Average esophageal length variables for patients with radiation esophagitis of grades $\geq 3(R E \geq G 3)$ and patients with $R E \leq G 2$. The error bars denote the 95\% standard error. Both groups were compared at each dose level using a two-sided Student's t-test $\left({ }^{*} p<0.05\right.$, **p<0.01, $* * * p<0.001)$.

\section{Discussion}

Both CCRT and AHRT are associated with a relatively high incidence rate of severe acute $\mathrm{RE}(1,3,7,8,11)$. From the biological viewpoint, the 2-Gy equivalent dose (EQD2) of the current AH-CCRT regimen (64 Gy/40 fractions/4 weeks) was $62.4 \mathrm{~Gy}$, calculated by the linear-quadratic model with $\alpha / \beta=10$ (12). However, the time factor was not considered in this calculation. Regarding esophagitis, the particular dose recovered per day was reported to be $0.8 \mathrm{~Gy} /$ day (13). The shortened RTT of 2 weeks (6 weeks to 4 weeks) can correspond to a $11.2 \mathrm{~Gy}$ dose escalation in $\mathrm{EQD} 2(\alpha / \beta=10 \mathrm{~Gy})$, and the calculated EQD2 add up to $73.6 \mathrm{~Gy}$ for the esophagus.

The incidence rate of grade $\geq 3 \mathrm{RE}$ in our study was $15.1 \%$ (24/159), which was relatively low despite a higher daily radiation dose (3.2 Gy/day). Byhardt et al. reported a $34 \%$ incidence rate of severe acute RE following hyperfractionated RT (69.6 Gy for 6 weeks twice daily) compared to $6 \%$ for once-daily chemoradiotherapy, and $1.3 \%$ for standard once-daily RT alone (11). Nyman et al. reported the higher incidence rate of severe $\mathrm{RE}$ with a twice-daily AH-CCRT regimen (64.6 Gy for 4.5 weeks with one week treatment break) compared to a once-daily regimen (16.3\% vs. 9.8\%) (14). Possible explanations include the fact that all our patients were treated with a concomitant boost technique. Particularly because most of the esophagus was not exposed to the second fraction of 1.2 Gy (phase 2), an AH-CCRT protocol using a concomitant boost technique can be less toxic than the hyperfractionated or accelerated hyperfractionated radiotherapy protocols.

Dose-volume histogram parameters that delineate cumulative dose over 40-50 Gy have been identified as being associated with severe RE in standard once-daily regimens $(8,15)$. An individual meta-analysis found that the $\mathrm{V}_{60}$ was the best predictor; a $\mathrm{V}_{60}$ of $<0.07 \%$ was associated with a $<5 \%$ risk of grade $\geq 3 \mathrm{RE}$, whereas a $\mathrm{V}_{60}$ of $\geq 17 \%$ conferred a $22 \%$ risk of grade $\geq 3 \mathrm{RE}(8)$. Our results, which are consistent with these findings, suggest that the risk of developing grade $\geq 3 \mathrm{RE}$ depends on the volume of the esophagus that is irradiated at a high dose (such as $60 \mathrm{~Gy}$ ) 
even when the AH-CCRT regimen is used. The incident rate of $37.8 \%$ in the patients whose $\mathrm{V}_{60}$ was $\geq 15 \%$ in this study was relatively high compared to $22 \%$ of those with a $\mathrm{V}_{60}$ of $\geq 17 \%$ reported in the meta-analysis (8). This difference might depend on the shortened RTT. The value of $\mathrm{V}_{60} \geq 15 \%$ in this study can correspond to a higher dose intensity in the conventional RT regimen. The AIC value for the Dmean was slightly worse than that for the $\mathrm{V}_{60}$, but was almost equivalent. The phase III intergroup Radiation Therapy Oncology Group 0617 trial recommended that the Dmean be maintained at $<34 \mathrm{~Gy}$ and that the $\mathrm{V}_{60}$ be calculated separately for each patient enrolled in the trial (7). We concur that a single consensus dosimetric constraint is insufficient to limit the risk to the esophagus. The length and volume parameters are conceptually distinct about whether we must delineate the entire esophagus or not. The length of the irradiated esophagus, as well as that of the irradiation field, are reportedly predictors of RE $(16,17)$; however, there is no consensus regarding the method of measurement of these parameters. The volume parameters had a better AIC value than the length of the esophagus in our study, although their advantage over volume metrics is unclear.

Patient characteristics associated with higher rates of severe acute esophagitis include age $\geq 70$ years (18), female sex (19), poor initial PS (19), low BMI (19) and (potentially) pretreatment dysphagia (19). In this study, only ECOG PS was significant. It seemed that the large impact of dose parameters on the occurrence of RE masked the potentially existing association between clinical characteristics and severe RE. In terms of ECOG PS, this result suggests that a good general condition renders the threshold of intervention for RE high. With respect to patient age, Soni et al. reported a lower incidence of RE in elderly patients undergoing definitive CCRT for NSCLC even after adjusting for chemotherapy administration $(\mathrm{OR}=0.93 ; 95 \% \mathrm{CI}=0.88-0.98)$ (20); their results were similar to ours. Although the intensity of chemotherapy may affect the incidence of RE in elderly patients undergoing concurrent treatment, they nevertheless appear to tolerate the AH-CCRT regimen, and should be offered the same options as younger patients if they maintain a good PS. Our chemotherapy regimens normally comprise cisplatin plus vinorelbine and carboplatin plus paclitaxel. Different chemotherapy regimens such as cisplatin plus docetaxel are also frequently used; such differences may influence the incidence rates of RE.

A limitation of our study was its retrospective design, which may have introduced selection bias into the dataset. In addition, patterns of care for adverse events may have changed in the long observation period. Therefore, the incidence rate of RE could not be universally applicable. Despite this limitation, the advantages of our study include the relative homogeneity of the RT regimen compared to previous studies.
While the AH-CCRT with a concomitant boost technique is one of the reasonable ways to escalate treatment intensity for NSCLC patients, pretreatment risk assessment of severe RE is essential. ECOG PS ( $\geq 1 v s .0)$ and the $\mathrm{V}_{60}$ were found to be significant risk factors for developing severe RE. Validation of our findings in a large independent patient cohort is warranted.

\section{Conflicts of Interest}

The Authors declare no conflicts of interest regarding this study.

\section{References}

1 Aupérin A, Le Péchoux C, Rolland E, Curran WJ, Furuse K, Fournel P, Belderbos J, Clamon G, Ulutin HC, Paulus R, Yamanaka T, Bozonnat MC, Uitterhoeve A, Wang X, Stewart L, Arriagada R, Burdett S and Pignon JP: Meta-analysis of concomitant versus sequential radiochemotherapy in locally advanced non-small-cell lung cancer. J Clin Oncol 28: 2181-2190, 2010.

2 Saunders M, Dische S, Barrett A, Harvey A, Gibson D and Parmar M: Continuous hyperfractionated accelerated radiotherapy (CHART) versus conventional radiotherapy in nonsmall-cell lung cancer: a randomised multicentre trial. CHART Steering Committee. Lancet 350: 161-165, 1997.

3 Saunders M, Dische S, Barrett A, Harvey A, Griffiths G and Palmar M: Continuous, hyperfractionated, accelerated radiotherapy (CHART) versus conventional radiotherapy in nonsmall cell lung cancer: mature data from the randomised multicentre trial. CHART Steering committee. Radiother Oncol 52: 137-148, 1999.

4 Fu XL, Jiang GL, Wang LJ, Qian H, Fu S, Yie M, Kong FM, Zhao S, He SQ and Liu TF: Hyperfractionated accelerated radiation therapy for non-small cell lung cancer: clinical phase I/II trial. Int J Radiat Oncol Biol Phys 39: 545-552, 1997.

5 Imamura $\mathrm{F}$, Konishi $\mathrm{K}$, Uchida J, Nishino K, Okuyama T, Kumagai T, Kawaguchi $\mathrm{Y}$ and Nishiyama K: Novel chemoradiotherapy with concomitant boost thoracic radiation and concurrent cisplatin and vinorelbine for stage IIIA and IIIB nonsmall-cell lung cancer. Clin Lung Cancer 15: 281-286, 2014.

6 Wada K, Kishi N, Kanayama N, Hirata T, Morimoto M, Konishi $\mathrm{K}$, Imamura $\mathrm{F}$, Teshima $\mathrm{T}$ and Ogawa $\mathrm{K}$ : Radiation dose escalation in accelerated hyperfractionated radiotherapy for stage III Non-small-cell Lung Cancer. Anticancer Res 38(10): 59515958, 2018

7 Bradley JD, Paulus R, Komaki R, Masters G, Blumenschein G, Schild S, Bogart J, Hu C, Forster K, Magliocco A, Kavadi V, Garces YI, Narayan S, Iyengar P, Robinson C, Wynn RB, Koprowski C, Meng J, Beitler J, Gaur R, Curran W Jr and Choy $\mathrm{H}$ : Standard-dose versus high-dose conformal radiotherapy with concurrent and consolidation carboplatin plus paclitaxel with or without cetuximab for patients with stage IIIA or IIIB non-smallcell lung cancer (RTOG 0617): a randomised, two-by-two factorial phase 3 study. Lancet Oncol 16: 187-199, 2015.

8 Palma DA, Senan S, Oberije C, Belderbos J, de Dios NR, Bradley JD, Barriger RB, Moreno-Jiménez M, Kim TH, Ramella S, Everitt S, Rengan R, Marks LB, De Ruyck K, Warner Aa nd Rodrigues G: Predicting esophagitis after chemoradiation 
therapy for non-small cell lung cancer: an individual patient data meta-analysis. Int J Radiat Oncol Biol Phys 87: 690-696, 2013.

9 Cox JD, Pajak TF, Asbell S, Russell AH, Pederson J, Byhardt RW, Emami B and Roach M 3rd: Interruptions of high-dose radiation therapy decrease long-term survival of favorable patients with unresectable non-small cell carcinoma of the lung: analysis of 1244 cases from 3 RTOG trials. Int J Radiat Oncol Biol Phys 27: 493-498, 1993.

10 Baggins B. Prescribing, recording and reporting photon beam therapy. Report 62; supplement to report 50. Bethesda: International Commission Radiation Units and Measurements; 1999.

11 Byhardt RW, Scott C, Sause WT, Emami B, Komaki R, Fisher B, Lee JS and Lawton C: Response, toxicity, failure patterns, and survival in five RTOG trials of sequential and/or concurrent chemotherapy and radiotherapy for locally advanced non-small-cell carcinoma of the lung. Int J Radiat Oncol Biol Phys 42: 469-478, 1998.

12 Hall EJ and Giaccia AJ: Radiobiology Radiologist. 7th ed. Philadelphia, PA: Lippincott Williams Wilkins, 2011.

13 Bentzen SM, Saunders MI and Dische S: From CHART to CHARTWEL in Non-small Cell Lung Cancer: Clinical Radiobiological Modelling of the Expected Change in Outcome. Clin Oncol 14: 372-381, 2002.

14 Nyman J, Friesland S, Hallqvist A, Seke M, Bergström S, Thaning L, Lödén B, Sederholm C and Wagenius G: How to improve loco-regional control in stages IIIa-b NSCLC? Lung Cancer 65: 62-67, 2009.

15 Kim TH, Cho KH, Pyo HR, Lee JS, Han JY, Zo JI, Lee JM, Hong EK, Choi IJ, Park SY, Shin KH, Kim DY and Kim JY: Dose-volumetric parameters of acute esophageal toxicity in patients with lung cancer treated with threedimensional conformal radiotherapy. Int J Radiat Oncol Biol Phys 62: 9951002, 2005.
16 Maguire PD, Sibley GS, Zhou SM, Jamieson TA, Light KL, Antoine PA, Herndon JE 2nd, Anscher MS and Marks LB: Clinical and dosimetric predictors of radiation-induced esophageal toxicity. Int J Radiat Oncol Biol Phys 45: 97-103, 1999.

17 Hirota S, Tsujino K, Endo M, Kotani Y, Satouchi M, Kado T, Hishikawa Y, Obayashi K, Takada Y, Kono M and Abe M: Dosimetric predictors of radiation esophagitis in patients treated for non-small-cell lung cancer with carboplatin/paclitaxel/ radiotherapy. Int J Radiat Oncol Biol Phys 51: 291-295, 2001.

18 Ahn SJ, Kahn D, Zhou S, Yu X, Hollis D, Shafman TD and Marks LB: Dosimetric and clinical predictors for radiationinduced esophageal injury. Int J Radiat Oncol Biol Phys 61: 335347, 2005.

19 Challand T, Thureau S, Dubray B and Giraud P: Esophageal toxicity of radiation therapy: clinical risk factors and management. Cancer Radiother 16: 364-371, 2012.

20 Soni PD, Boonstra PS, Schipper MJ, Bazzi L, Dess RT, Matuszak MM, Kong FM, Hayman JA, Ten Haken RK, Lawrence TS, Kalemkerian GP and Jolly S: Lower incidence of esophagitis in the elderly undergoing definitive radiation therapy for lung cancer. J Thorac Oncol 12: 539-546, 2017.

Received November 21, 2018

Revised November 28, 2018

Accepted November 29, 2018 